\title{
Health parameters and their association with price in young calves sold at auction for veal operations in Québec, Canada
}

\author{
S. Marquou, ${ }^{1,2}$ L. Blouin, ${ }^{3}$ H. Djakite, ${ }^{3}$ R. Laplante, ${ }^{3}$ and S. Buczinski ${ }^{1 *}$ \\ ${ }_{1}^{1}$ Département des Sciences Cliniques, Faculté de Médecine Vétérinaire, Université de Montréal, Saint-Hyacinthe J2S 2M2, Québec, Canada \\ ${ }^{2}$ VetAgroSup, Campus Agronomique, 63370 Lempdes, France \\ ${ }^{3}$ Producteurs Bovins du Québec, Longueuil, J4H 4G2, Québec, Canada
}

\section{ABSTRACT}

The veal calf industry in Québec depends on young calves' availability at auction. Most of these calves come from dairy farms. The aim of this cross-sectional study was to determine the effect of clinical anomalies and other calf characteristics on their sale price. A total of 3,820 calves from 5 different auctions were included in this observational study. The calves were examined by a veterinarian on arrival at the auction and screened for umbilical anomalies, the presence of nasal or eye discharge, joint abnormality, diarrhea, appearance of neonatal characteristics (compatible with age less than $1 \mathrm{wk}$ ), and general health status mainly based on the presence of depression and dehydration. The final multivariable model included 5 different variables (calf weight, sex, breed, abnormal joints, and general health status) and the interaction between sex and general health status. The presence of abnormal joints and unhealthy characteristics was negatively associated with standardized price. Female calves and mixed breed beef calves were positively associated with standardized price. Finally, the calves' weight was associated with standardized price in a quadratic fashion. Ongoing or previous diarrhea had no effects on standardized price. This study will be helpful for both dairy and veal producers for improving the quality of calves sold to the Québec auction market.

Key words: veal, auction market

\section{INTRODUCTION}

Dairy calves can either be kept by dairy farmers for replacement purposes or be sold to veal calf production facilities. Male calves form the basis of the veal

Received November 26, 2018

Accepted February 8, 2019.

*Corresponding author: s.buczinski@umontreal.ca industry. In Canada, the province of Québec is a major player in veal calf production, producing around $80 \%$ of Canadian veal calves (Producteurs de Bovins du Québec, 2018). The male calves can be managed differently from the female calves in Canadian dairy farms (Renaud et al., 2017). Because of the low value of these animals, they can receive a lower level of care than replacement heifers (such as lower amount of feed in $17 \%$ of farms, or no distribution of colostrum in $9 \%$ of sampled farms), which can predispose them to future health issues while at veal farms (Renaud et al., 2017). Calves with clinical health problems are frequently observed on the day of arrival at veal farms and these clinical abnormalities are associated with early mortality (Pempek et al., 2017; Renaud et al., 2018a). Depression, dehydration, diarrhea, respiratory problems, and navel inflammation are commonly reported problems upon arrival (Pempek et al., 2017) and during the feeding period (Brscic et al., 2012; Pardon et al., 2012).

Health problems can be exacerbated by transportation from the farm to the veal facility (Mormede et al., 1982). Commingling and limited access to feed and water can also exacerbate these anomalies (Todd et al., 2000; Fisher et al., 2014). Calves with low BW upon arrival have been found at higher risk of hampered breathing during the early feeding period in Europe (Brscic et al., 2012). A recent Ontario study found that lighter calves bought at a lower price when compared with the monthly average price were at a higher risk of early mortality $(<21 \mathrm{~d}$ after arrival) in veal farm units than heavier calves (Winder et al., 2016). In the province of Québec, dairy calves are sold at specialized auctions across the province. Few data are available on dairy calf health at these auctions before the animals are sold and transported to the veal farm units.

The price paid per crude weight is one of the main economic drivers of the veal calf industry because large veal integrators are sensitive to input costs (Sans and Fontguyon, 2009). Prices are driving the industry much more than welfare issues. For these reasons, it is important to know the effects of health and welfare indicators 
on calf prices. Knowing which signs or calf characteristics are associated with better prices would also be an incentive for dairy producers to improve the value of sold calves and indirectly to promote calf health and welfare.

This study investigated the health parameters and characteristics of dairy calves sold at 5 of the 6 most important dairy calf auctions across the province of Québec, Canada. The main objective of the study was to assess the association between individual covariates and the purchase price of calves at auction.

Our main hypothesis was that calves with abnormal clinical findings on the day of the auction would be sold at a lower purchase price when accounting for the general variability of prices. We wanted to quantify this negative effect as well as that of any other covariate associated with purchase price. A secondary objective of the study was to determine clinical characteristics associated with abnormal clinical signs that are present in calves on the day of the auction.

\section{MATERIALS AND METHODS}

This study was performed from August 21 to September 15, 2017, during the sale of dairy calves at 5 auctions in Québec. The general information available at the auction was collected from each site (sites A to E). For each calf, information recorded included the breed (dairy or beef mixed breed based on observed phenotype) and the sex. The calves' weights were recorded on the day of the sale. Unfortunately, because of the absence of specific/reliable information on date of birth, their exact age could not be determined.

The calves were assessed by experienced veterinarians who routinely work in calf and veal calf operations. The assessment grid was presented to the participating veterinarians to ensure agreement between the different veterinarians involved in the different sites. However, it was not possible to test inter-rater agreement. The visual and physical examination was performed just after the calves had been weighed. As many calves as possible were examined during every auction with the restriction of not disrupting or slowing the sale process. For this reason, it was not possible to examine all calves sold on a specific day. The physical assessment focused on specific clinical signs or health parameters that indicated either an ongoing health problem or specific risk factors for disease, with the aim of assessing the effect of these factors on calf price. In the absence of a specific date of birth for these calves, indirect indicators of very young age were assessed by the veterinarians, including the appearance of the external umbilical cord (wet navel: yes vs. no) as well as general appearance [e.g., calves still wet or showing difficulty standing (neonatal characteristics: yes vs. no)]. The examination focused on the presence of umbilical anomalies (including swelling, discharge or evidence of pain; omphalitis: yes vs. no), the presence of nasal or eye discharge (discharge: yes vs. no), the presence of hock/carpus swelling or wounds (abnormal joints: yes vs. no), and the presence of current or previous diarrhea based on hide cleanliness and appearance of feces (diarrhea: yes vs. no). Finally, the veterinarian gave a general qualitative assessment concerning calf health. The calves were diagnosed as unhealthy if they appeared either very dirty, severely depressed or dehydrated, weak with difficulty standing or walking (or both), very thin or presented signs of abnormal breathing patterns, or with the presence of any wound (unhealthy: yes or no). A general health score was obtained based on the sum of abnormal findings (health score ranging theoretically from 0 to 7 ).

The data obtained during the veterinary examination was recorded on a spreadsheet (Excel, Windows, Redmond, WA) and general information from the auction was added based on each calf's identification, site, and date of auction. The general information obtained from the sale spreadsheet included the purchase weight and the price paid per pound [Canadian dollars (Can\$)/ lb], which was converted in Can\$ per kilogram of BW.

\section{Statistical Analyses}

Descriptive statistics and other models were used to describe the available data set using SAS v9.3 (SAS Institute Inc., Cary, NC) and R (R Core Team, 2013). In all regression models, the auction site was considered as a fixed effect to account for data structure and specific unmeasured auction market characteristics (Dohoo et al., 2009).

\section{Factors Affecting Price Paid Per Calf}

In the province of Québec, the purchase price of calves varies from one week to another due to specific characteristics of the dairy and veal industry, as previously reported for Ontario veal calves (Winder et al., 2016). We defined a standardized price that accounted for specific variation in the price paid for the ith calf during a specific day as previously determined in an Ontarian study (Winder et al., 2016). The mean purchase price per pound $[\mathrm{Can} \$ / \mathrm{lb}$ converted in $\mathrm{Can} \$ / \mathrm{kg}$ with 1 pound $(\mathrm{lb})=0.455 \mathrm{~kg}$ ] for the jth day based on the official mean price reported by the Producteurs de Bovins du Québec (Québec Beef Producers available online at http://bovin.qc.ca/info-prix/bovin-de-reforme -et-veau-laitier/quotidien/) was subtracted from the 
ith calf price per kilogram. We used this transformed variable (standardized price, Equation [1]) throughout the study as the dependent variable in our models, with the aim of accounting for market volatility.

$$
\begin{aligned}
& \text { Standardized } \text { price }_{\mathrm{ij}}=\text { price }(\mathrm{Can} \$ / \mathrm{kg})_{\mathrm{i}} \\
& \text { - mean_price_day_j (Can } \$ / \mathrm{kg}) \text {. }
\end{aligned}
$$

This analysis allowed direct comparison with a previous study on Ontario veal calves published in this journal (Winder et al., 2016).

After verification of normality assumption by the Shapiro-Wilk test, the mean (SD) weight was calculated as [47.5 kg $(6.9 \mathrm{~kg})$ or $104.5 \mathrm{lbs}(15.1 \mathrm{lbs})]$. A centered weight (weight_ct in $\mathrm{kg}$ ) was created for use in all regression models.

$$
\text { Weight_ct } \mathrm{i}_{\mathrm{i}}=\text { weight }_{\mathrm{i}}-47.5,
$$

where weight_ct ${ }_{i}$ is the centered weight for the ith calf. We have used this centered weight throughout the manuscript to make our inference using a mean calf reference as well as for decreasing correlation when relationship with weight included a polynomial term (Dohoo et al., 2009). A multivariable linear regression model was used to model the association between the standardized price and covariates measured at the calf level. The correlation between potential numerical and ordinal covariates of the model was assessed using Spearman's rho coefficient for numerical and ordinal variables to avoid the collinearity issue (using Spearman's rho $>0.6$ as a threshold for defining collinearity between 2 variables). For other categorical variables, collinearity was tested by looking at the variance inflation factor after using these variables as potential regressors. A threshold of variance inflation factor $\geq 5$ was considered to indicate collinearity (O'brien, 2007). Univariable analysis was first performed between the dependent variable (standardized price) and other covariates. The association was tested using univariable linear regression analysis. Quadratic regression was used to model the association between weight_ct and standardized price to improve residual normality. Variables associated with the dependent variable during the univariable analysis $(P<0.2)$ were included in the multivariable model. The linear model was built using lme4 package in R software (Bates et al., 2014).

The general multivariable model framework was as follows:

$$
\begin{gathered}
\text { Standardized price }=\beta_{0}+\beta_{1} \mathrm{X}_{1}+\ldots \\
+\beta_{\mathrm{n}} \mathrm{X}_{\mathrm{n}}=[\beta] \times[\mathrm{X}] .
\end{gathered}
$$

The dependent variable is the standardized price, $[\beta]$ is a vector of regression coefficient, and $[\mathrm{X}]$ is the associated covariates' matrix. A manual backward stepwise method was used to test the plausible interaction between health parameters and calf covariates (breed or sex). Biologically plausible interactions were tested, especially concerning the interaction between the sex or breed and clinical features. Significance was set at $P<0.05$. The fit of the model was assessed using a distribution plot and normally distributed residuals. The coefficient of determination of the final model $\left(\mathrm{R}^{2}\right)$ was also obtained as well as the relative effect of the significant covariates on the variance partition of the model using the ratio of type III sum of squares of covariates divided by the model total sum of squares. For better interpretation of the multivariable model, we used the predicted least squares means for categorical variables that accounted for unbalanced characteristics of the data set (Lenth, 2016).

\section{Clinical Signs}

The association between specific clinical signs on the day of the auction and other covariates was determined using multivariable logistic regressions models as explained in Equation [4]. The dependent variable was the health parameter of interest (abnormal vs. normal finding) and potential regressors were those previously used for the standardized price analysis.

Logit (probability of abnormal health parameter) $=$

$$
\beta_{0}+\beta_{1} X_{1}+\ldots+\beta_{n} X_{n}=[\beta] \times[X],
$$

where $[\beta]$ is a vector of regression coefficient and $[\mathrm{X}]$ is the associated covariates' matrix. Univariable associations were first tested using the chi-squared test for categorical data and univariable logistic regression models were performed for assessing the association between health parameters and continuous data (e.g., weight). Variables with $P<0.2$ were retained to build the multivariable models using a manual backward stepwise method, and final statistical significance was set at $P<0.05$. The site was considered the fixed variable in all models, to account for data structure. The interaction between auction sites and sex was tested in all models as well as interaction between statistically significant clinical signs and auction sites as potentially relevant interactions. Variables were considered as potential confounders in the model when the regression coefficient varied by more than 30\% (Lava et al., 2016). The fits of the different models were assessed using the Hosmer and Lemeshow goodness of fit test (Hosmer et al., 1997). 


\section{RESULTS}

\section{Descriptive Statistics}

Information on sales was retrieved for 5,281 calves from the 5 auction sites. After merging this information with the clinical information, a total of 3,820 calves were available for the study, representing $72 \%$ of calves sold during these days. The descriptive statistics of the included calves are depicted in Table 1. The calves' price depending on the day and auction site is represented in Figure 1, showing the relative volatility of the market price during the study period. Two of the 5 auction sites (site $\mathrm{A}$ and $\mathrm{E}$ ) sold $>85 \%$ of the calves studied. The prices were comparable between in examined and nonexamined calves (Supplemental Figure S1; https://doi.org/10.3168/jds.2018-16051).

Despite the fact that the vast majority of calves were male, females represented $13 \%$ of calves sold. Mixed dairy and beef breed phenotypes were included in the analyses. At the calf level, the most commonly reported anomalies were the presence of signs of omphalitis (20.3\% of calves), neonatal characteristics (12.3\%), and the general appearance of an unhealthy animal (7.7\%). Abnormal joints were uncommonly reported $(0.4 \%)$. The proportions of calves with specific health anomalies relative to their health score are depicted in Figure 2. The correlogram between categorical/ordinal variables revealed the lack of significant collinearity between the different variables, except between clinical score and omphalitis or neonatal characteristics. The health score was therefore not included in the multivariable analyses.

\section{Standardized Price Model}

The results of the univariable and multivariable analyses are summarized in Tables 2 and 3. The centered weight was associated with standardized price with a quadratic relationship, as shown in Figure 3. The final multivariable model included the calves' centered weight (quadratic), sex, breed, abnormal joints, and unhealthy clinical signs. Although uncommon, the presence of abnormal joints had a strong negative effect on standardized price. The interaction between sex and unhealthy calves was also included in the model, with healthy females being sold at a higher price than male calves (Figure 4 ). The model $\mathrm{R}^{2}$ was 0.40 , the partition of the variance was mainly explained by the weight and its polynomial (58\%) and the breed type (30\%). The remaining predictors (auction sites, sex, joint, and health status) only accounted for $12 \%$ of the model variance.

Table 1. Descriptive clinical characteristics of 3,820 young calves sold in Québec auction market

\begin{tabular}{|c|c|c|}
\hline Variable & Description & No. of calves $(\%)$ \\
\hline \multirow{2}{*}{ Sex } & Male & $3,094(81.0)$ \\
\hline & Not available & $259(6.8)$ \\
\hline \multirow{2}{*}{ Breed } & Mixed breed & $574(11.0)$ \\
\hline & Not available & $259(6.8)$ \\
\hline Health_score & 0: no abnormal clinical feature & $2,192(57.4)$ \\
\hline \multirow{2}{*}{$\begin{array}{l}\text { Sum of abnormal clinical signs } \\
\text { (possible range } 0-7 \text { ) }\end{array}$} & 3: 3 abnormal clinical features & $63(1.6)$ \\
\hline & 4: 4 abnormal clinical features & $13(0.3)$ \\
\hline \multirow[t]{2}{*}{ Abnormal_joint } & Normal joint & $3,805(99.6)$ \\
\hline & Abnormal joint (swollen or wound) & $15(0.4)$ \\
\hline \multirow[t]{2}{*}{ Diarrhea } & Absence of diarrhea & $3,581(93.7)$ \\
\hline & Evidence of ongoing or recent diarrhea & $239(6.3)$ \\
\hline Discharge & Absence of nasal or ocular discharge & $3,726(97.5)$ \\
\hline \multirow[t]{2}{*}{ Unhealthy } & Apparently healthy calf & $3,524(92.3)$ \\
\hline & Unhealthy features & $296(7.7)$ \\
\hline \multirow[t]{2}{*}{ Wet_navel } & Dry umbilical stalk & $3,562(93.2)$ \\
\hline & Wet umbilical stalk or navel & $258(6.8)$ \\
\hline Site & A & $1,933(50.6)$ \\
\hline \multirow{4}{*}{ Auction market site } & $\mathrm{B}$ & $158(4.1)$ \\
\hline & $\mathrm{C}$ & $202(5.3)$ \\
\hline & $\mathrm{D}$ & $208(5.4)$ \\
\hline & $\mathrm{E}$ & $1,319(34.5)$ \\
\hline
\end{tabular}




\section{Health Parameter Logistic Regression Models}

The different multivariable logistic regression models showing the association between the calves' covariates and clinical signs are summarized in Table 4. Interestingly, we observed a protective effect of being a female calf on the odds of omphalitis and wet navel as well as on the odds of being unhealthy. However, the female calves were at a higher risk than males of having signs of diarrhea. Centered weight was negatively associated with the probability of being judged as having neonatal characteristics and being unhealthy. It was not possible to create a specific model for joint abnormality due to the low number of abnormal cases $(\mathrm{n}=15)$ and convergence issues.

\section{DISCUSSION}

This study gives original insights into specific parameters affecting the price of young calves to be grown as milk- or grain-fed veal calves. Rather than looking only at sale information, health parameters were considered as potential factors affecting price. Information on calves' characteristics has mostly been gathered from studies at the time of arrival in the veal facility (Pempek et al., 2017; Renaud et al., 2018a,c). In the present study, we identified several characteristics associated with standardized price. Our results could therefore help the Québec calf industry to understand (1) what types of anomalies are present in calves sold at Québec auctions and therefore (2) how the quality of calves can be improved by targeting calf characteristics that are positively associated with the standardized price.

We found that umbilical problems were present in 1 in 5 calves sold, which was slightly lower than rate of $27 \%$ reported for Ohio veal calves (Pempek et al., 2017 ) and the rate of $24.5 \%$ found in an Ontarian study (Renaud et al., 2018c). The percentage of calves with diarrhea was only $6.3 \%$, which was roughly half the previously reported prevalence of $12.7 \%$ of calves in Ontario (Renaud et al., 2018c) and 14\% of calves in Ohio (Pempek et al., 2017). We found that $7.7 \%$ of calves had a generally unhealthy appearance. This parameter was based on general appearance and is a composite of depression and hydration status. Dehydration has previously been found in $35 \%$ of calves entering veal calf facilities in Ohio (Pempek et al., 2017) and at a much higher level $(50 \%)$ in Ontarian veal calves (Renaud et al., 2018a). Besides specific variation from one area to another, the differences between the current study and these 2 previous studies in terms of clinical health parameters may be due to the fact that the clinical as-

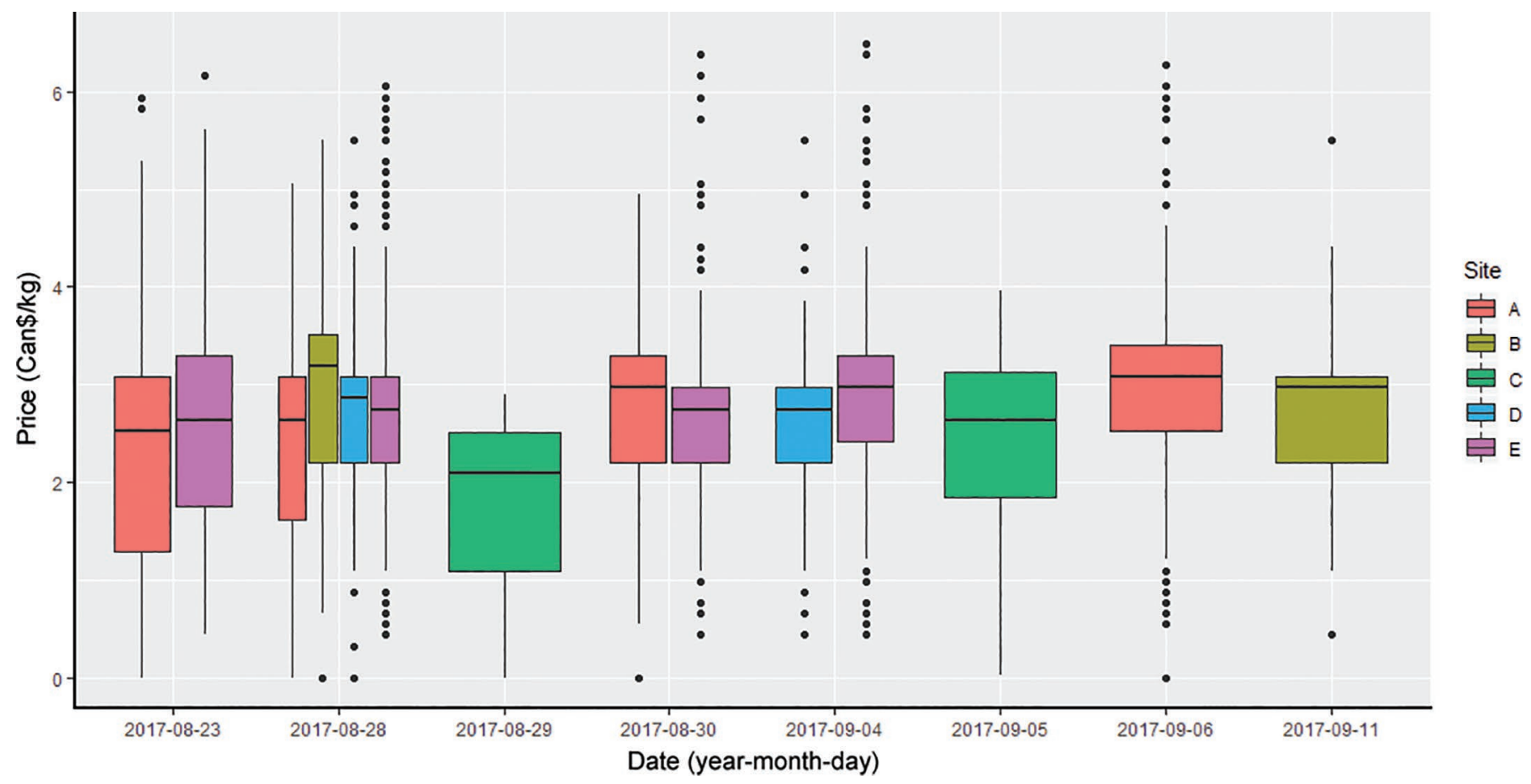

Figure 1. Price paid per live weight in calves sold in 5 dairy calf auctions in Québec, Canada, in summer 2017. The price is the price paid per live weight pound $(\mathrm{Can} \$ / \mathrm{kg})$ for calves in the 5 different auctions. The width of the boxplot is proportional to the total number of calves sold at that specific site/day. The width of the box is proportional to the sample size, the height of the box represents the interquartile range, and the line within the box represents the mean price. The whisker size represents the $1.5 \times$ interquartile range value. The dots represent calves outside of these ranges. 


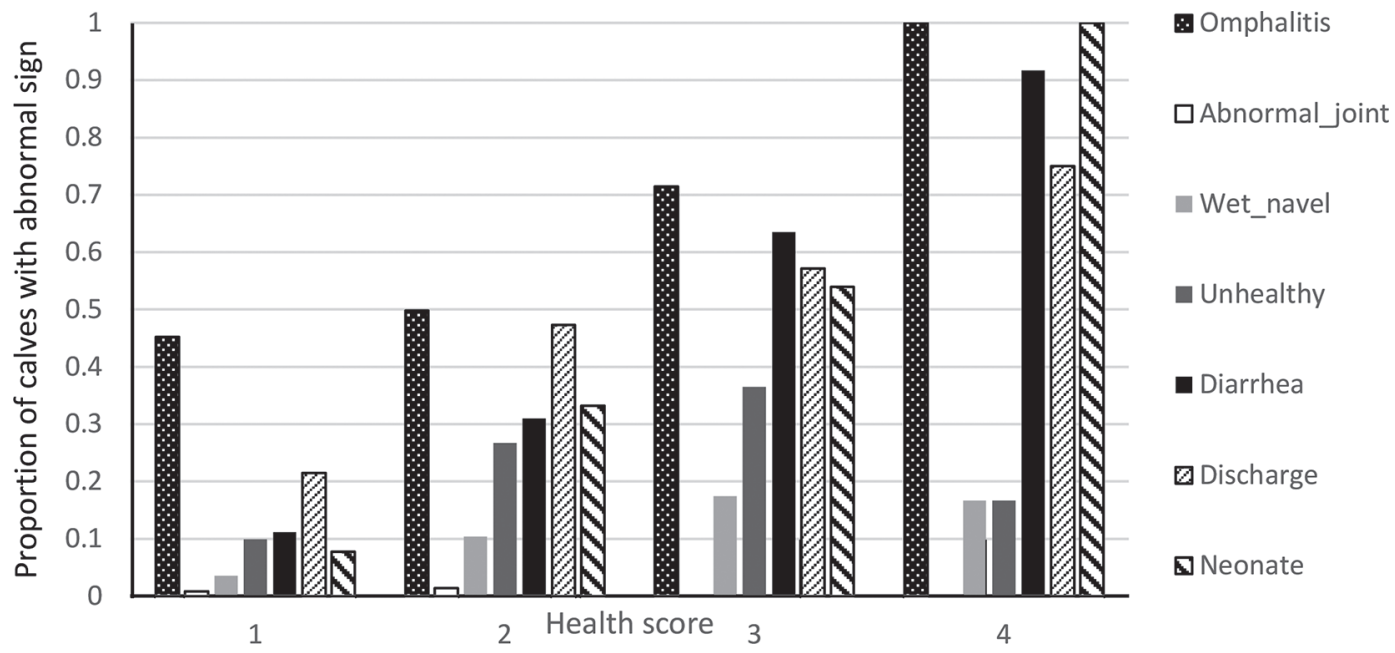

Figure 2. Proportion of calves sold in Québec dairy calf auction market with specific abnormal health parameters based on their health score. The health score represents the number of clinical abnormalities for a specific calf.

sessment was performed directly at the auction site and not on arrival at the veal facility. The delay in assessment caused by lairage before the auction, commingling after the sale and then transportation to the veal calf farms may exacerbate several clinical conditions that were not detected upon arrival of calves at the auction. Body weight losses and dehydration commonly occur in feed-deprived calves and increased with the total duration of the journey (Fisher et al., 2014); markers of stress such as plasma cortisol and noradrenaline also increased (Uetake et al., 2011). Reducing weight loss by providing a good quality meal just before transportation should be encouraged in dairy farmers based on the association between weight and standardized price (Figure 4), especially for calves that weigh between 47.5 and $61.4 \mathrm{~kg}$.

The production costs of veal calves are mainly driven by their purchase price and feed costs (Sans and Fontguyon, 2009). The relative importance of feed cost is much higher in milk-fed versus grain-fed veal calves due to the high price of milk replacer used in white veal calves. For these reasons, it is easy to understand why buyers may be risk adverse when buying calves with some degree of anomaly associated with a higher risk of poor performance in the veal farm unit. The calves' weight was associated with standardized price per kilogram in a quadratic fashion, meaning that both lighter and heavier calves sold for lower prices than average calves. Calves with low weight on arrival have previously been found to be at higher risk of dying early in 2 Ontario studies (Winder et al., 2016; Renaud et al., 2018a). A low BW can also be a marker of weight loss due to fasting and dehydration, which are also associated with decreased veal performance (Marcato et al.,
2018). The negative effect on price of heavier calves is a new finding. The meaning of this finding cannot be formally proved, but it is possible that heavier calves have a higher probability of having previously been sick at their farm of origin and thus not fit for transportation at the target sale age. This could have delayed their sale and might be associated with a higher perceived risk of problems in the veal unit. Their lower economic value in terms of the possibility of adapting their digestive system to a specific veal diet after spending longer on their farm of origin may also be a reason for this negative association (Berends, 2014).

Interestingly, sex and breed were associated with purchase price with breed having a stronger effect on standardized price. The females were sold at a higher price per crude weight than males. It is difficult to determine exactly what causes this difference, but the perceived added value of being female could be based on possibly better care, fewer health anomalies, better passive transfer of immunity than in male calves, or a combination of these. A prospective study on 52 Ontario dairy farms that supply veal farms reported that clinical anomalies were higher in male than female calves, at 41 versus $29 \%$, respectively (Renaud et al., $2018 \mathrm{~b}$ ). We found that female calves had lower odds of a wet navel or omphalitis as well as lower odds of being unhealthy when compared with male calves. In contrast, female calves had higher odds of diarrhea than male calves. In a Belgian study on 3,519 calves in 10 commercial veal herds, the female calves had a lower risk of mortality than male calves with a hazard ratio of death of 0.4 (95\% CI 0.2-0.9) using a multivariable Cox proportional analysis including herd as a frailty term (Pardon et al., 2013). This added value of female 
Table 2. Univariable analysis association with standardized price paid for calves [Canadian dollars (Can\$)/ $\mathrm{kg}$ ] in Québec auction markets

\begin{tabular}{|c|c|c|c|c|}
\hline Predictor & Variable level $^{1}$ & Estimate & $\mathrm{SE}$ & $P$-value \\
\hline \multirow[t]{3}{*}{ Weight (lbs) } & Intercept & 0.323 & 0.018 & $<0.001^{2}$ \\
\hline & Weight_ct & 0.072 & 0.002 & $<0.001^{2}$ \\
\hline & Weight_ct_sq & -0.004 & 0.000 & $<0.001^{2}$ \\
\hline \multirow[t]{3}{*}{ Sex } & Intercept & 0.103 & 0.019 & $<0.001^{2}$ \\
\hline & Male & Referent & - & $<0.001^{2}$ \\
\hline & Female & 0.257 & 0.053 & \\
\hline \multirow[t]{3}{*}{ Breed } & Intercept & -0.018 & 0.018 & 0.30 \\
\hline & Dairy & Referent & - & $<0.001^{2}$ \\
\hline & Mixed breed & 1.311 & 0.051 & \\
\hline \multirow[t]{6}{*}{ Health score } & Intercept & 0.030 & 0.026 & 0.24 \\
\hline & 0 & Referent & - & $<0.001^{2}$ \\
\hline & 1 & -0.085 & 0.044 & $0.053^{3}$ \\
\hline & 2 & -0.320 & 0.070 & $<0.001^{3}$ \\
\hline & 3 & -0.587 & 0.156 & $<0.001^{3}$ \\
\hline & 4 & -1.030 & 0.340 & $0.003^{3}$ \\
\hline \multirow[t]{3}{*}{ Diarrhea } & Intercept & -0.034 & 0.021 & 0.095 \\
\hline & No diarrhea & Referent & - & 0.36 \\
\hline & Diarrhea & -0.075 & 0.082 & \\
\hline \multirow[t]{3}{*}{ Omphalitis } & Intercept & -0.045 & 0.022 & 0.04 \\
\hline & No omphalitis & Referent & - & 0.54 \\
\hline & Omphalitis & 0.030 & 0.049 & \\
\hline \multirow[t]{3}{*}{ Wet navel } & Intercept & -0.034 & 0.021 & 0.10 \\
\hline & Dry navel & Referent & - & 0.34 \\
\hline & Wet navel & -0.076 & 0.079 & \\
\hline \multirow[t]{3}{*}{ Discharge } & Intercept & -0.039 & 0.020 & 0.054 \\
\hline & No ocular or nasal discharge & Referent & - & 0.95 \\
\hline & Ocular or nasal discharge & -0.009 & 0.128 & \\
\hline \multirow[t]{3}{*}{ Neonate } & Intercept & 0.022 & 0.021 & 0.30 \\
\hline & No neonatal characteristic & Referent & - & $<0.001^{2}$ \\
\hline & Neonatal characteristic & -0.495 & 0.060 & \\
\hline \multirow[t]{3}{*}{ Unhealthy } & Intercept & -0.010 & 0.021 & 0.61 \\
\hline & Apparently healthy & Referent & - & $<0.001^{2}$ \\
\hline & Unhealthy & -0.367 & 0.074 & \\
\hline \multirow[t]{3}{*}{ Joint } & Intercept & -0.033 & 0.020 & 0.09 \\
\hline & Normal joint & Referent & - & $<0.001^{2}$ \\
\hline & Abnormal joint & -1.451 & 0.317 & \\
\hline \multirow[t]{6}{*}{ Site } & Intercept & -0.137 & 0.028 & $<0.001$ \\
\hline & $\mathrm{A}$ & Referent & - & $<0.001^{2}$ \\
\hline & $\mathrm{B}$ & 0.148 & 0.101 & $0.14^{3}$ \\
\hline & $\mathrm{C}$ & -0.148 & 0.090 & $0.10^{3}$ \\
\hline & $\mathrm{D}$ & 0.040 & 0.089 & $0.65^{3}$ \\
\hline & $\mathrm{E}$ & 0.281 & 0.044 & $<0.001^{3}$ \\
\hline
\end{tabular}

${ }^{1}$ Weight_ct $=$ weight $-47.5(47.5 \mathrm{~kg}$ was the mean weight of the calves $) ;$ weight_ct_sq $=$ weight_ct $\times$ weight_ct.

${ }^{2}$ Variable associated with standardized price $(\mathrm{Can} \$ / \mathrm{kg})$ in univariable analysis (using $P<0.2$ level for inclusion). The health score was not kept in multivariable modeling due to high correlation with other clinical signs.

${ }^{3} P$-value for comparison between the referent variable category and the category of interest in case of 3 or more possible categories for the same variable.

calves was only valid for apparently healthy animals, as demonstrated by the interaction found in the multivariable model.

The breed type was also strongly associated with standardized price. European studies have previously shown the added value of beef breeds for veal farms in terms of hot carcass weight and ADG (Pardon et al., 2013). The use of beef semen is not a common practice in Canadian dairy farms, but the results of the current study indicate that using semen from beef breeds could increase the return from calf sales at the dairy producer level, as previously shown in an Italian study
(Dal Zotto et al., 2009). Using this breeding strategy for animals of lower genetic merit, or in dairy farms that are not raising their replacement stock, could also mitigate the extra cost of using sexed semen for highly valuable cows (De Vries et al., 2008).

Of the clinical parameters that were initially assessed, only abnormal joints and an unhealthy appearance of the calf were negatively associated with the standardized price paid per weight. Abnormal joints were only infrequently found but had an important negative effect on purchase price. Pardon et al. (2013) showed that veal calves with a clinical diagnosis of arthritis had 
Table 3. Characteristics associated with standardized price $(\mathrm{Can} \$ / \mathrm{kg})$ in calves sold in Québec auction market for veal operations

\begin{tabular}{|c|c|c|c|c|}
\hline Predictor $^{1}$ & Level & Estimate & $\mathrm{SE}$ & $P$-value \\
\hline Intercept & & 0.127 & 0.022 & $<0.001$ \\
\hline \multirow[t]{5}{*}{ Site } & A & Referent & - & $<0.001$ \\
\hline & B & 0.001 & 0.070 & \\
\hline & $\mathrm{C}$ & -0.107 & 0.064 & \\
\hline & $\mathrm{D}$ & 0.045 & 0.064 & \\
\hline & $\mathrm{E}$ & 0.184 & $0.031^{2}$ & \\
\hline Weight_ct $(\mathrm{kg})$ & & 0.071 & $<0.001$ & $<0.001$ \\
\hline Weight_ct_sq $\left(\mathrm{kg}^{2}\right)$ & & -0.004 & $<0.001$ & $<0.001$ \\
\hline \multirow[t]{2}{*}{ Sex } & Male & Referent & - & 0.001 \\
\hline & Female & 0.148 & 0.046 & \\
\hline \multirow[t]{2}{*}{ Breed } & Dairy & Referent & - & $<0.001$ \\
\hline & Mixed breed & 1.210 & 0.046 & \\
\hline \multirow[t]{2}{*}{ Abnormal_joint } & Normal joint & Referent & - & $<0.001$ \\
\hline & Abnormal joint & -1.371 & 0.242 & \\
\hline \multirow[t]{2}{*}{ Unhealthy } & Apparently healthy & Referent & - & $<0.001$ \\
\hline & Apparently not healthy & -0.307 & 0.055 & \\
\hline Sex $\times$ unhealthy & & 0.371 & 0.183 & 0.04 \\
\hline
\end{tabular}

${ }^{1}$ Weight_ct $=$ weight $-47.5(47.5 \mathrm{~kg}$ was the mean weight of the calves); weight_ct_sq $=$ weight_ct $\times$ weight_ct.

${ }^{2}$ Site E was significantly different $(P<0.001)$ from other sites based on post hoc calculation tests.

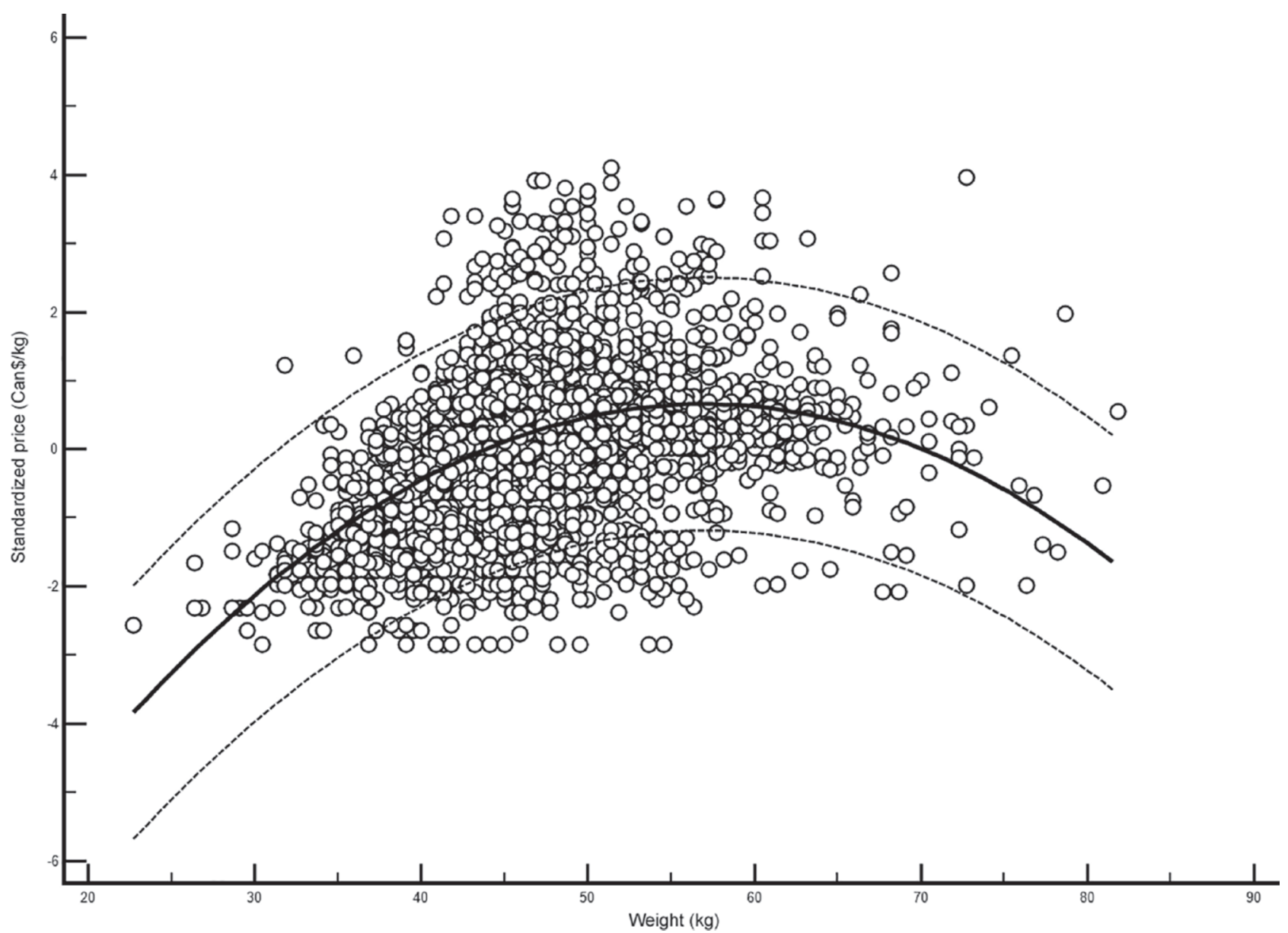

Figure 3. Univariable analysis of the association between standardized price and calf weight. The quadratic linear relationship between the standardized price (price paid for the calf per $\mathrm{kg}$ minus mean price of the day) and the centered weight of calves (weight of calf - 47.5) is indicated as a solid line. The $95 \%$ prediction interval is delimited between the 2 dotted lines. The $\mathrm{x}$-axis is representing nontransformed weight for an easier interpretation. 
a high risk of mortality (23.1\%) during the feeding period. The affected calves that did not die in that study had increased odds of lower fat cover and poor carcass quality as well as decreased hot carcass weight. This increased risk of poor performance could be the cause of the lower purchase price for this category of calves. The general health appearance was a general variable measuring different health characteristics with a known negative effect on calves' health, for example dehydration (Renaud et al., 2018c) or abnormal respiratory efforts (Pardon et al., 2013). Although not a specific sign of disease, such characteristics can easily be detected by buyers used to observing calves and may be indicators of a relatively advanced stage of disease that may require intervention with possible negative outcomes. However, it was not possible to collect more specific information on the individual characteristics of calves with such abnormal signs, which is a limitation of these clinical indicators. Interestingly, other more specific clinical signs such as umbilical infection and evidence of diarrhea were not associated with standardized price. Interestingly, although commonly observed, umbilical infection was not associated with a lower ADG in veal calves (Renaud et al., 2018c). Moreover, due to the rapidity of the sale process it is difficult to determine the sensitivity of navel disease assessment (i.e., capacity to detect calves with abnormal umbilicus) by the buyers, especially for animals with limited umbilical swelling. Surprisingly, evidence of ongoing or previous diarrhea was not associated with the standardized price paid. It is important to remember that no specific distinction was made between calves having active diarrhea versus calves with poor hide cleanliness. Recent Canadian research has shown the poor association between diarrhea and hide cleanliness in calves arriving at a veal calf facility (Graham et al., 2018). Due to the data collection at the auction markets, it was not possible to determine if the better calves in terms of price per kilogram or health status were more profitable in the veal feeding period in terms of feed efficiency, antimicrobial treatments required, mortality, and carcass characteristics. Having this information available would be helpful to further improve the price paid for the calves with the highest economic return for the veal feeders creating a virtuous circle between dairy producers and veal calves' feeders. Additional tests such as indicators of passive immunity transfer (that can be assessed using a simple refractometer) have also been associated with negative health outcomes in a Flemish study (Pardon et al., 2015). The added value of these additional tests associated with calves' outcomes should be further quantified on both welfare and economic effects to justify a premium for dairy producers and an incentive for better calf care.

This study comes with some specific limitations due to the study design. First, since different veterinarians examined the calves and no specific agreement between veterinarians was performed, we cannot exclude a veterinarian effect, which would be partly confounded with the site effect (because it was impossible to have

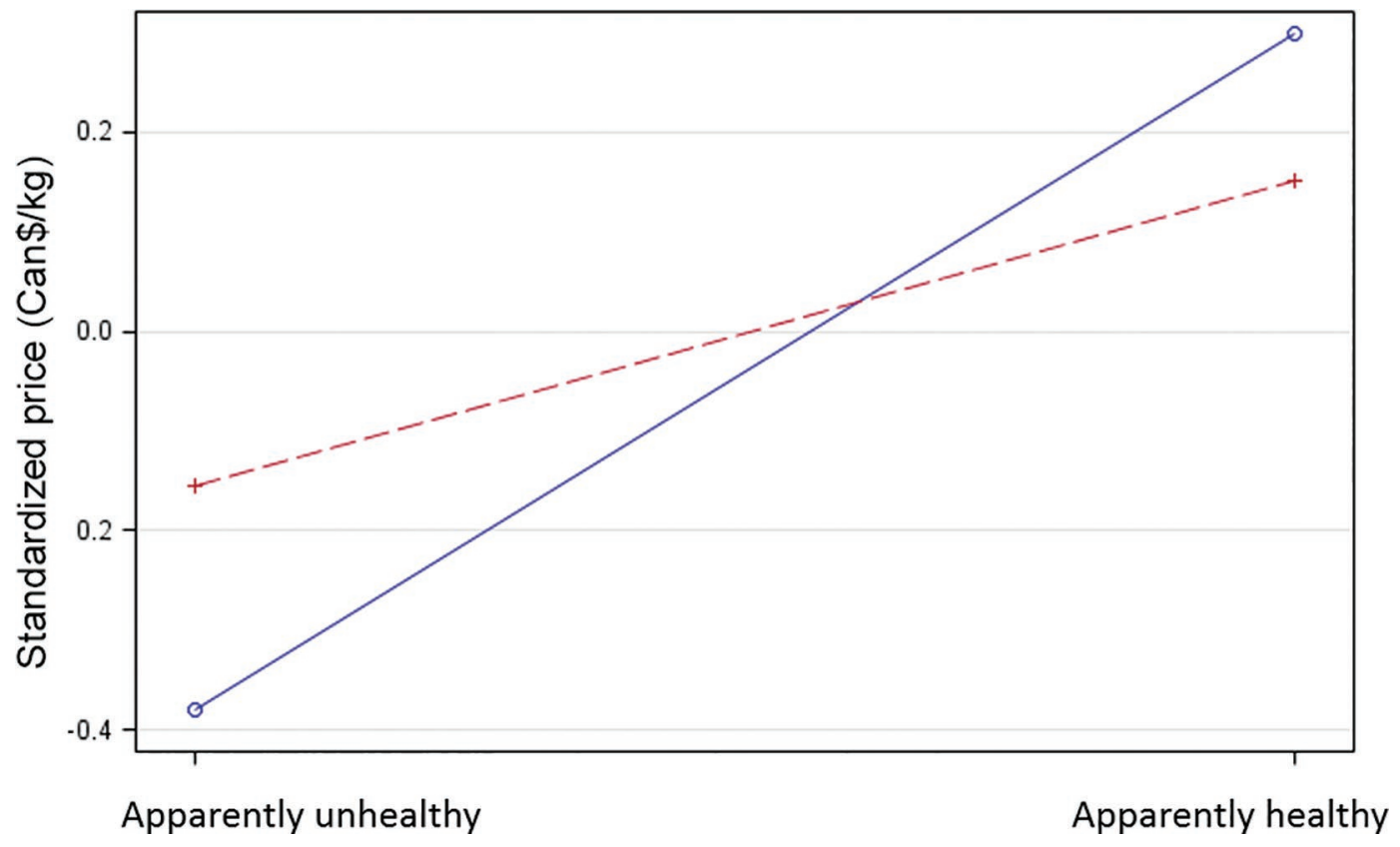

Figure 4. Interaction between sex and the general health status of the calves on the day of the sale and its association with standardized price. The female calves (continuous line) were sold at a higher standardized price than males calves (dotted line) when healthy, but this difference was reversed when the calves were apparently unhealthy. 
Table 4. Multivariable logistic regression models for the association between clinical signs and characteristics of calves

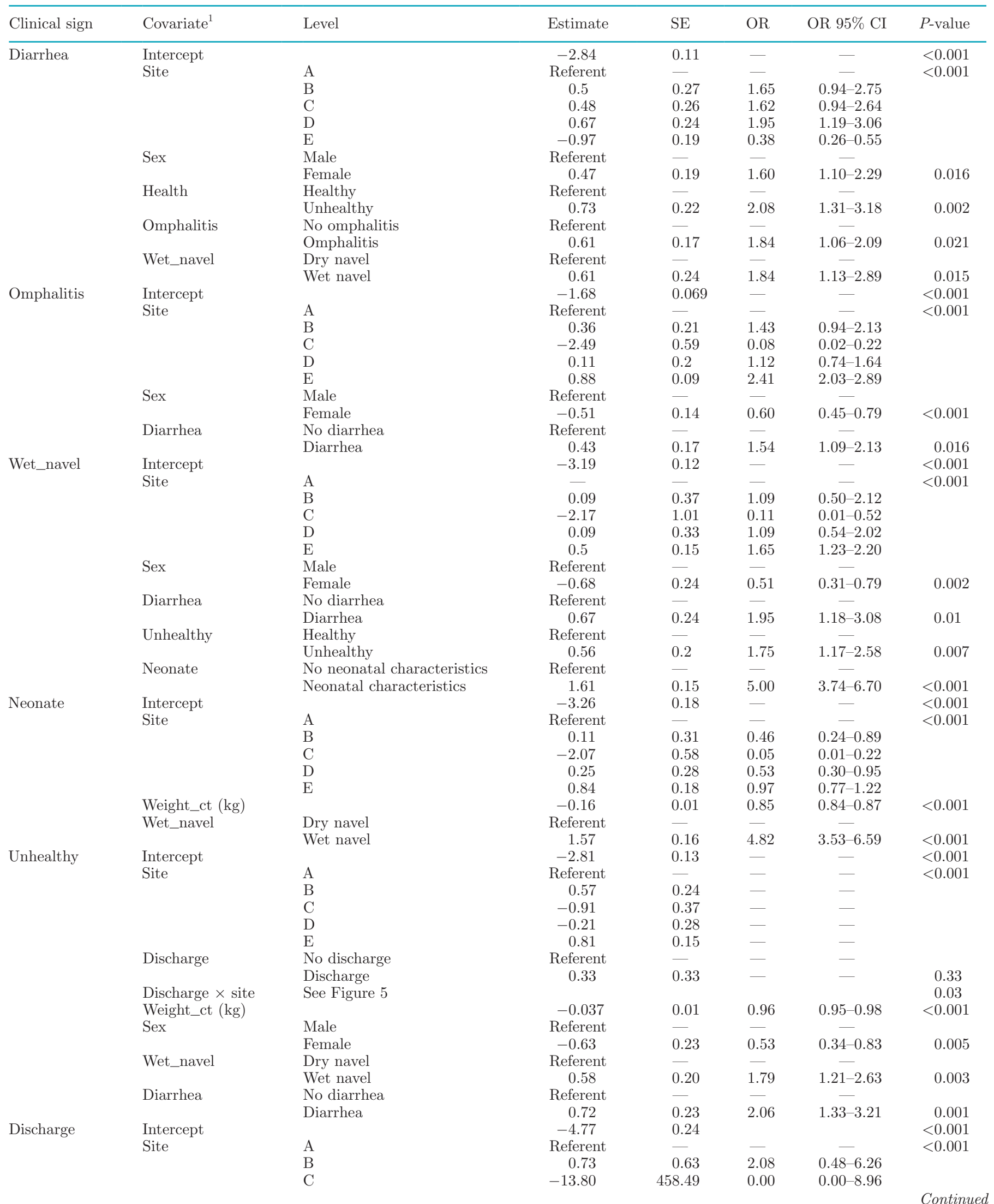


Table 4 (Continued). Multivariable logistic regression models for the association between clinical signs and characteristics of calves

\begin{tabular}{|c|c|c|c|c|c|c|c|}
\hline Clinical sign & Covariate $^{1}$ & Level & Estimate & SE & OR & OR $95 \%$ CI & $P$-value \\
\hline & \multirow[b]{2}{*}{ Unhealthy } & $\mathrm{E}$ & 1.82 & 0.27 & 6.17 & $3.7-10.9$ & \\
\hline & & Healthy & Referent & - & - & - & \\
\hline
\end{tabular}

${ }^{1}$ Weight_ct $=$ weight -47.5 (47.5 kg was the mean weight of the calves). The odds ratio $(\mathrm{OR})$ given is per increase of $1 \mathrm{~kg}$ above the mean weight.

the same person performing the examination in these multiple sites in the same period). However, because the monitored clinical signs were dichotomous (normal vs. abnormal) and experienced veterinarians were recruited, we think that the probability of this event would be low. Some parameters such as hydration and body condition detection were not standardized by a score but based on veterinary skills. This may have led to a lack of sensitivity to detect mild cases, but we think that these signs are specific when performed by a veterinarian. Second, it was not possible to score all calves present on a specific day due to the need to avoid disrupting the flow of sales. For this reason and the fact that the calves screened were not selected purely at random, we cannot exclude a risk of bias. However, we consider this risk as low. Since this study was cross-sectional, we cannot make any inference on the association between standardized price or health parameters and production outcome. Previous North
American studies have shown an association between calf characteristics on the day of entry to the veal farm units. A trend for lower-price calves being at higher risk of early mortality has been reported previously (Winder et al., 2016). Moreover, it was impossible to determine whether the type of veal operation was associated with calf price. Milk-fed veal calves are generally required to show higher homogeneity and quality than grain-fed milk calves because the costs of production are much higher than for grain-fed milk calves. For this reason, it is easy to understand why the buyer would be more risk adverse for milk-fed veal calves than grainfed veal calves. Unfortunately, this information was not available in our study. Finally, it was impossible to determine any causal relationship in the associations we observed.

In conclusion, we found that several calf characteristics are associated with the standardized price paid for calves in Québec dairy calf auctions. The results there-

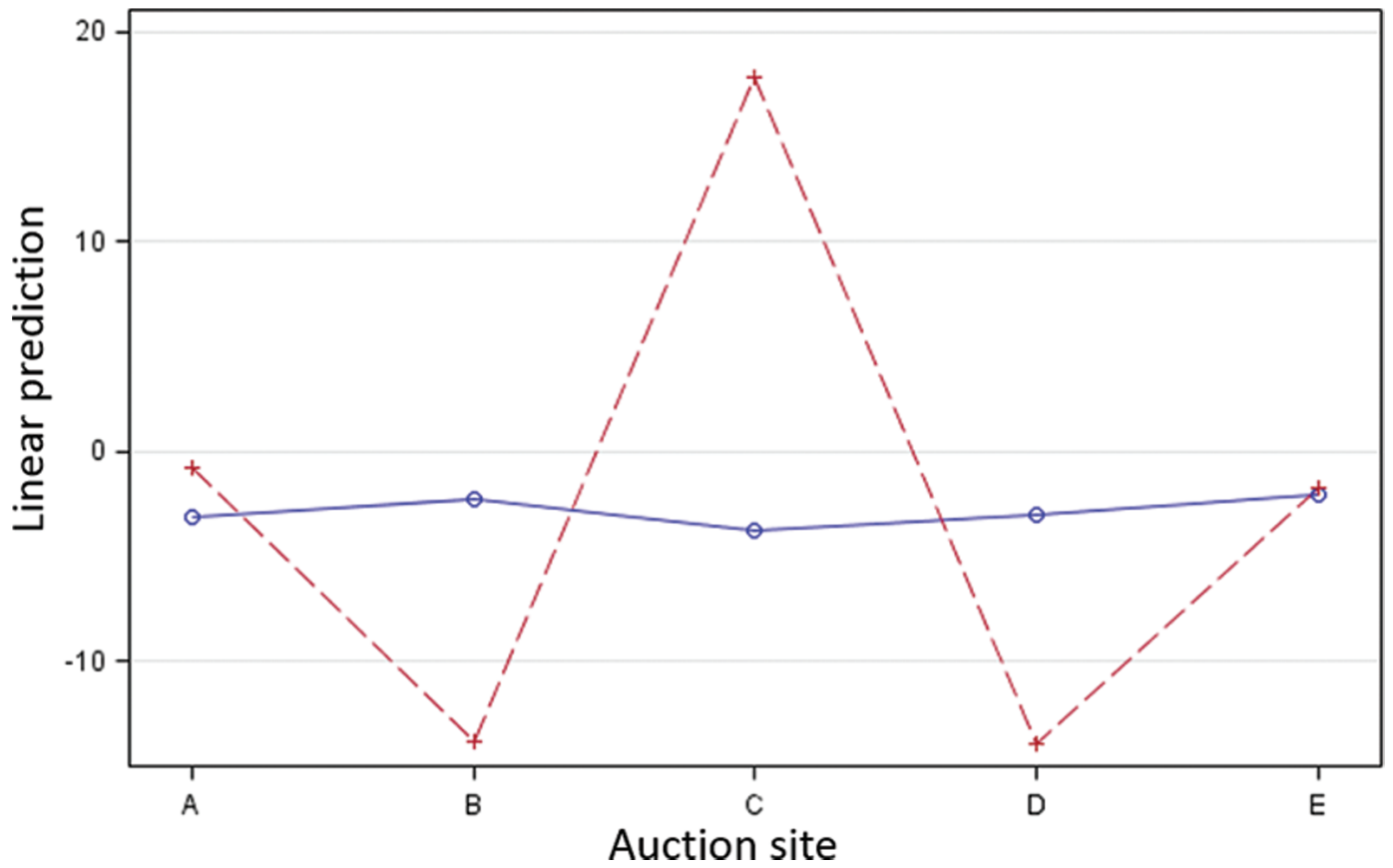

Figure 5. Interaction between the presence of eye or nasal discharge and auction market site for prediction of the logit probability of being unhealthy. The calves with the presence of discharge are represented as a continuous line. The auction sites A, B, C, D, and E are indicated on the x-axis. The y-axis represents the probability of being unhealthy on the logit scale controlling for covariates in the final model (Table 4 ). 
fore indicate possible ways to improve calf price while accounting for market volatility. Improving the calves' value is of importance not only for the dairy farmers but also for the veal producers. The added value of better calf characteristics needs to be determined in more detail at the veal farm level to create a win-win situation for both dairy farmers and veal producers. This will not only improve the calves' welfare and productivity but also the sustainability of the veal calf industry.

\section{ACKNOWLEDGMENTS}

This project was funded by the Cull Cows and Bob Calves Producers' Research and Development Fund, Les Producteurs de Bovins du Québec, Quebec's cattle producers' association, Canada. The authors thank Michel Savard and Marie-Ève Paradis from the Quebec Association of Veterinarians; Jean Durocher, Valacta, Charles Bernier, Philippe Voghell, Nicolas BernardBrouillard, Jérôme Paquet, Guy Laquerre, and Pierre Ruest from the Producteurs bovins du Québec; and members of the Cull Cows and Bob Calves committee. The authors also thank the different auctions at which the study took place (Marchés d'animaux de l'Est, Encans de Saint-Hyacinthe, Coopérative des marchés d'animaux vivants du Bas Saint-Laurent, Marchés d'animaux vivant Veilleux, and Encans de Sawyerville).

\section{REFERENCES}

Bates, D., M. Mächler, B. Bolker, and S. Walker. 2014. Fitting linear mixed-effects models using lme4. arXiv preprint arXiv:1406.5823.

Berends, H. 2014. Nutrient utilization, dietary preferences, and gastrointestinal development in veal calves: Interactions between solid feed and milk replacer. PhD Thesis. Animal Nutrition Group, Wageningen University, Wageningen, the Netherlands.

Brscic, M., H. Leruste, L. F. Heutinck, E. A. Bokkers, M. WolthuisFillerup, N. Stockhofe, F. Gottardo, B. J. Lensink, G. Cozzi, and C. G. Van Reenen. 2012. Prevalence of respiratory disorders in veal calves and potential risk factors. J. Dairy Sci. 95:2753-2764.

Dal Zotto, R., M. Penasa, M. De Marchi, M. Cassandro, N. Lopez-Villalobos, and G. Bittante. 2009. Use of crossbreeding with beef bulls in dairy herds: Effect on age, body weight, price, and market value of calves sold at livestock auctions. J. Anim. Sci. 87:3053-3059.

De Vries, A., M. Overton, J. Fetrow, K. Leslie, S. Eicker, and G. Rogers. 2008. Exploring the impact of sexed semen on the structure of the dairy industry. J. Dairy Sci. 91:847-856.

Dohoo, I. R., W. Martin, and H. E. Stryhn. 2009. Veterinary Epidemiologic Research. VER Inc., Charlottetown, Canada.

Fisher, A. D., B. H. Stevens, M. J. Conley, E. C. Jongman, M. C. Lauber, S. J. Hides, G. A. Anderson, D. M. Duganzich, and P. D. Mansell. 2014. The effects of direct and indirect road transport consignment in combination with feed withdrawal in young dairy calves. J. Dairy Res. 81:297-303.

Graham, A. N., D. L. Renaud, T. F. Duffield, and D. F. Kelton. 2018. Short communication: Calf cleanliness does not predict diarrhea upon arrival at a veal calf facility. J. Dairy Sci. 101:3363-3366.
Hosmer, D. W., T. Hosmer, S. Le Cessie, and S. Lemeshow. 1997. A comparison of goodness-of-fit tests for the logistic regression model. Stat. Med. 16:965-980.

Lava, M., B. Pardon, G. Schupbach-Regula, K. Keckeis, P. Deprez, A. Steiner, and M. Meylan. 2016. Effect of calf purchase and other herd-level risk factors on mortality, unwanted early slaughter, and use of antimicrobial group treatments in Swiss veal calf operations. Prev. Vet. Med. 126:81-88.

Lenth, R. V. 2016. Least squares means: The R package lsmeans. J. Stat. Softw. 69:1-33.

Marcato, F., H. van den Brand, B. Kemp, and K. van Reenen. 2018. Evaluating potential biomarkers of health and performance in veal calves. Front. Vet. Sci. 5:133.

Mormede, P., J. Soissons, R. M. Bluthe, J. Raoult, G. Legarff, D. Levieux, and R. Dantzer. 1982. Effect of transportation on blood serum composition, disease incidence, and production traits in young calves. Influence of the journey duration. Ann. Rech. Vet. 13:369-384.

O'brien, R. M. 2007. A caution regarding rules of thumb for variance inflation factors. Qual. Quant. 41:673-690.

Pardon, B., J. Alliet, R. Boone, S. Roelandt, B. Valgaeren, and P. Deprez. 2015. Prediction of respiratory disease and diarrhea in veal calves based on immunoglobulin levels and the serostatus for respiratory pathogens measured at arrival. Prev. Vet. Med. 120:169-176.

Pardon, B., K. De Bleecker, M. Hostens, J. Callens, J. Dewulf, and P. Deprez. 2012. Longitudinal study on morbidity and mortality in white veal calves in Belgium. BMC Vet. Res. 8:26.

Pardon, B., M. Hostens, L. Duchateau, J. Dewulf, K. De Bleecker, and P. Deprez. 2013. Impact of respiratory disease, diarrhea, otitis and arthritis on mortality and carcass traits in white veal calves. BMC Vet. Res. 9:79.

Pempek, J., D. Trearchis, M. Masterson, G. Habing, and K. Proudfoot. 2017. Veal calf health on the day of arrival at growers in Ohio. J. Anim. Sci. 95:3863-3872.

Producteurs de Bovins du Québec. 2018, May. Deux filieres portrait global 2017. http://bovin.qc.ca/la-production/portrait-global/ coup-doeil/.

R Core Team. 2013. Version 3.3.3. R: A language and environment for statistical computing. R Foundation for Statistical Computing, Vienna, Austria. http://www.R-project.org/.

Renaud, D. L., T. Duffield, S. LeBlanc, D. Haley, and D. Kelton. 2017. Management practices for male calves on Canadian dairy farms. J. Dairy Sci. 100:6862-6871.

Renaud, D. L., T. Duffield, S. LeBlanc, D. Haley, and D. Kelton. 2018a. Clinical and metabolic indicators associated with early mortality at a milk-fed veal facility: A prospective case-control study. J. Dairy Sci. 101:2669-2678.

Renaud, D. L., D. Kelton, S. LeBlanc, D. Haley, and T. Duffield. 2018b. Calf management risk factors on dairy farms associated with male calf mortality on veal farms. J. Dairy Sci. 101:17851794 .

Renaud, D. L., M. W. Overton, D. F. Kelton, S. J. LeBlanc, K. C. Dhuyvetter, and T. F. Duffield. 2018c. Effect of health status evaluated at arrival on growth in milk-fed veal calves: A prospective single cohort study. J. Dairy Sci. 101:10383-10390.

Sans, P., and G. D. Fontguyon. 2009. Veal calf industry economics. Rev. Med. Vet. 160:420-424.

Todd, S. E., D. J. Mellor, K. J. Stafford, N. G. Gregory, R. A. Bruce, and R. N. Ward. 2000. Effects of food withdrawal and transport on 5- to 10-day-old calves. Res. Vet. Sci. 68:125-134.

Uetake, K., T. Tanaka, and S. Sato. 2011. Effects of haul distance and stocking density on young suckling calves transported in Japan. Anim. Sci. J. 82:587-590.

Winder, C. B., D. F. Kelton, and T. F. Duffield. 2016. Mortality risk factors for calves entering a multi-location white veal farm in Ontario, Canada. J. Dairy Sci. 99:10174-10181. 